\title{
Pengaruh Konsentrasi KOH terhadap Jenis Zeolit Sintetis dari Abu Dasar Batubara dengan Metode Peleburan Alkali Hidrotermal
}

\author{
Hamidah, Afdhal Muttaqin* \\ Jurusan Fisika FMIPA Universitas Andalas, Padang \\ Kampus Unand Limau Manis, Pauh, Padang 25163 \\ *hamidahnailah@gmail.com
}

\begin{abstract}
ABSTRAK
Telah dilakukan sintesis zeolit dari abu dasar batubara menggunakan metode peleburan alkali hidrotermal dengan $\mathrm{KOH}$ sebagai aktivator. Konsentrasi $\mathrm{KOH}$ yang digunakan adalah 0,1 mol, 0,3 mol dan 0,5 mol. Peleburan alkali dilakukan pada temperatur $550{ }^{\circ} \mathrm{C}$ selama 1 jam dan proses hidrotermal dilakukan pada temperatur $100{ }^{\circ} \mathrm{C}$ selama 6 jam dengan variasi media kristalisasi aquades dan air laut. Sampel hasil sintesis dicuci dengan aquades hingga mencapai $\mathrm{pH}$ 9-10. Zeolit yang dihasilkan dikarakterisasi menggunakan XRD. Hasil karakterisasi menunjukkan bahwa zeolit yang terbentuk menggunakan media kristalisasi aquades adalah potassium aluminum silicate (megakalsilit), leucit, muskovit dan masih banyak kandungan kuarsa. Sampel yang disintesis menggunakan media kristalisasi air laut mengandung megakalsilit, leucit, muskovit dan sodalit.

Kata kunci: Potassium aluminum silicate, megakalsilit, konsentrasi.
\end{abstract}

ABSTRACT

Synthesis of zeolites from coal bottom ash with $\mathrm{KOH}$ as an activator with fusion step followed by hydrothermal treatment method have been carried. KOH concentrations were 0,1 mol, 0,3 mol and 0,5 mol. Alkali melting process was carried out at $550^{\circ} \mathrm{C}$ for 1 hour while hydrothermal process at temperature of $100{ }^{\circ} \mathrm{C}$ for 6 hours using two crystallization media; distilled water and sea water. The synthesized samples were washed with distilled water until pH of 9-10. The type of zeolite were characetrised using XRD. XRD results show that the zeolite synthesized using distilled water as crystallized media contains potassium aluminum silicate (megacalsilite), leucit, muscovit with addition of still high contents of quartz. While the samples using sea water crystallization media contains potassium megacalsilite, muscovite, leucite and sodalite.

Keywords: Potassium aluminum silicate, megacalsilite, concentration.

\section{PENDAHULUAN}

Zeolit merupakan kristal alumina silika terhidrasi yang mempunyai struktur kerangka tiga dimensi terbuka dan berongga yang berisi ion logam dan molekul air yang bergerak bebas (Mumbton, 1985). Zeolit terbagi atas zeolit alam dan zeolit yang disintesis di laboratorium. Zeolit sintetis dapat dibuat dari bahan yang mengandung unsur aluminium (Al) dan silikon ( $\mathrm{Si}$ ) sebagai rangka utama dari sebuah zeolit. Limbah batubara, baik itu abu dasar maupun abu layang, banyak digunakan dalam proses pembuatan zeolit karena mengandung $\mathrm{Al}$ dan $\mathrm{Si}$ yang cukup besar. Abu dasar sendiri memiliki kandungan $\mathrm{SiO}_{2}$ (silika) dan $\mathrm{Al}_{2} \mathrm{O}_{3}$ (alumina) sebesar 57,236\% $\left(\mathrm{SiO}_{2}\right)$ dan 33,172\% $\left(\mathrm{Al}_{2} \mathrm{O}_{3}\right)(\mathrm{Sari}, 2016)$ dan abu layang sebesar $26,85 \%\left(\mathrm{Al}_{2} \mathrm{O}_{3}\right)$ dan $51,8 \%\left(\mathrm{SiO}_{2}\right)$ (Fatiha, 2013). Pembuatan zeolit dari abu dasar telah menghasilkan berbagai jenis zeolit sintetis, seperti zeolit A, zeolit Na-X, zeolit Na-P, sodalit, kuarsa, hidroksisodalit (Oktaviani dan Muttaqin, 2015), zeolit X, P, A dan sodalit (Nikmah, 2008), zeolit Na-X, Na-P, hidroksisodalit dan kuarsa (Lestari dan Muttaqin, 2015), zeolit Na-X, Na-P, hidroksisodalit (Waleza dan Muttaqin, 2015), zeolit Na, Na-A, P dan unnamed zeolite (Sriwahyuni dkk., 2015). Hingga saat ini telah ditemukan tidak kurang dari 176 jenis zeolit sintetis (Baerlocher dkk., 2007).

Dalam pemanfaatannya, zeolit sintetis dimanfaatkan pada berbagai aplikasi seperti sebagai absorben, penukar ion, katalis dan aplikasi bidang elektronika. Pemanfaatkan aplikasi zeolit dalam bidang elektronika dikembangkan sebagai sumber material semikonduktor dimana nilai konduktivitas listrik dari zeolit dipengaruhi oleh jenis zeolit dan derajat kristalinitasnya (Lestari dan Muttaqin, 2015).

Sriwahyuni dkk. (2015) melakukan penelitian sintesis zeolit dari bahan abu dasar menggunakan metode peleburan alkali hidrotermal dengan menggunakan aktivator $\mathrm{NaOH}$. Media kristalisasi yang digunakan adalah aquades dan NaAlO2 (Natrium Aluminat) dengan 
temperatur peleburan $550{ }^{\circ} \mathrm{C}, 750{ }^{\circ} \mathrm{C}$ dan $950{ }^{\circ} \mathrm{C}$. Zeolit yang dihasilkan dengan media kristalisasi aquades adalah zeolit tipe $\mathrm{Na}$ sedangkan zeolit yang dihasilkan dengan media kristalisasi $\mathrm{NaAlO}_{2}$ adalah zeolit tipe $\mathrm{Na}-\mathrm{A}$, zeolit $\mathrm{P}$ dan unnamed zeolite.

Pembuatan zeolit berbahan abu layang dengan aktivator $\mathrm{KOH}$ dilakukan oleh Fansuri dkk. (2009), yaitu menggunakan KOH (Kalium Hidroksida) sebagai sumber kation sekaligus medium basa. Penulis mendapatkan zeolit tipe khabazit (CHA) untuk temperatur hidrotermal rendah (mendekati $100{ }^{\circ} \mathrm{C}$ ) dan phillipsit (PHI) untuk temperatur hidrotermal tinggi (mendekati $180{ }^{\circ} \mathrm{C}$ ). Selain itu Fansuri dkk. (2009) juga mendapatkan nilai kemampuan penukar kation (Cation Exchange Capacity) dari zeolit yang meningkat seiring lamanya waktu hidrotermal kedua. Penelitian Fansuri dkk. (2009) dan Sriwahyuni dkk. (2015), menunjukkan bahwa aktivator menentukan jenis zeolit yang dihasilkan jika dilakukan penelitian menggunakan aktivator $\mathrm{KOH}$ dan menggunakan aquades dan air laut sebagai media kristalisasinya.

Penelitian yang dilakukan adalah sintesis zeolit dari abu dasar batubara mengkombinasikan penggunaan $\mathrm{KOH}$ dengan metode yang dilakukan oleh Sriwahyuni dkk., (2015). Variasi mol KOH yang digunakan sebesar $0,1 \mathrm{~mol}, 0,3 \mathrm{~mol}$ dan $0,5 \mathrm{~mol}$. Variasi mol dimaksudkan untuk menghasilkan zeolit sintetis dengan tingkat kemurnian yang tinggi. Karakterisasi struktur untuk menentukan jenis zeolit dilakukan menggunakan XRD.

\section{METODE}

Bahan yang digunakan adalah: abu dasar batubara, $\mathrm{KOH}$, air laut, akuades, Aquabidestilat. Bahan dasar yang digunakan diayak terlebih dahulu dan dicampur dengan $\mathrm{KOH}$ 0,1 mol, 0,3 mol, dan 0,5 mol. Sampel yang telah dicampur merata dimasukkan ke dalam furnace bertemperatur $550^{\circ} \mathrm{C}$ selama $1 \mathrm{jam}$. Selanjutnya, $20 \mathrm{~g}$ sampel dilarutkan dengan $250 \mathrm{ml}$ aquabidestilat. Sampel diaduk dengan menggunakan magnetic stirrer selama 1 jam. Setelah diaduk, sampel dimasukkan ke dalam botol polietilen dan di-aging selama 2 jam pada temperatur $25{ }^{\circ} \mathrm{C}$, lalu disaring dengan menggunakan kertas whatman 42 dan diambil ekstraknya. Ekstrak sampel dari hasil penyaringan dilarutkan dengan dua jenis larutan yang berbeda. Tiga sampel pertama dilarutkan dengan $50 \mathrm{~mL}$ air laut dan 3 sampel kedua dilarutkan dengan $50 \mathrm{~mL}$ aquades. Sampel kemudian diaduk menggunakan magnetic stirrer selama satu jam. Setelah itu sampel dimasukkan ke dalam reaktor hidrotermal (Teflon Autoclave) pada temperatur $100{ }^{\circ} \mathrm{C}$ selama 6 jam. Setelah dioven, sampel dikeluarkan dari reaktor hidrotermal, dipisahkan dari filtratnya, lalu dicuci dengan aquades hingga mendapatkan $\mathrm{pH}$ 9-10. Setelah diperoleh $\mathrm{pH}$ yang diinginkan, sampel kemudian dikeringkan pada temperatur $100{ }^{\circ} \mathrm{C}$ selama 12 jam.

\section{HASIL DAN DISKUSI}

\subsection{Komposisi dan Jenis Zeolit Sintesis}

Penentuan komposisi dan jenis zeolit yang terbentuk dari keenam sampel dilakukan dengan menggunakan XRD (X-Ray Difractometer). Puncak difraksi yang didapatkan dari data pengukuran dicocokkan dengan standar difraksi sinar-X yaitu International Center of Diffraction Database (ICDD). Pola difraksi sinar-X pada Gambar 1 menunjukan bahwa hasil sintesis zeolit pada variasi mol $\mathrm{KOH} 0,1 \mathrm{~mol}, 0,3 \mathrm{~mol}$ dan 0,5 mol dengan media kristalisasi aquades berhasil menumbuhkan Potassium Aluminum Silicate (megakalsilit), muskovit, leucit dan sodalit. Berdasarkan hasil pada Gambar 1 terlihat puncak-puncak kurva difraksi yang dihasilkan oleh masing-masing sampel mengalami pergeseran yang signifikan. Titik intensitas tertinggi dari pola difraksi yang dihasilkan diperoleh pada sudut $2 \theta=26,5699(0,1 \mathrm{~mol}), 2 \theta=$ $26.7843(0,3 \mathrm{~mol})$ dan $2 \theta=28.6693(0,5 \mathrm{~mol})$, terutama pada sudut $2 \Theta=28.6693$ yang sesuai dengan puncak karakteristik dari standar ICCD nomor 00-033-0988.

Pada variasi media kristalisasi sintesis zeolit dengan media kristalisasi aquades masih banyak terdapat kuarsa ( $\mathrm{SiO} 2$ ) yaitu $41,9 \%$ untuk $0,1 \mathrm{~mol} \mathrm{KOH}, 63,2 \%$ untuk $0,3 \mathrm{~mol} \mathrm{KOH}$ dan $92 \%$ untuk $0,5 \mathrm{~mol} \mathrm{KOH}$ yang merupakan kandungan dari abu dasar batubara (Gambar 1 dan Tabel 1). Konsentrasi megakalsilit pada 0,5 mol KOH adalah $92 \%$ dan konsentrasi kuarsanya adalah 8\%. Hal ini menunjukkan bahwa semakin besar jumlah mol $\mathrm{KOH}$ yang digunakan dalam sintesis zeolit menggunakan media kristalisasi aquades maka konsentrasi kuarsa yang 
terdapat pada sampel akan semakin berkurang. Masih terdapatnya senyawa-senyawa kandungan abu dasar batubara mengindikasikan bahwa proses pembentukkan zeolit tidak terjadi secara maksimal, karena tidak semua senyawa $\mathrm{Al}_{2} \mathrm{O}_{3}$ dan $\mathrm{SiO}_{2}$ yang berikatan dan membentuk zeolit. Hal ini juga didapatkan oleh Jumaeri dkk. (2009) dengan menggunakan variasi konsentrasi $\mathrm{NaOH}$ sebesar 2 mol, 4 mol dan 6 mol dimana hasil yang didapatkan oleh Jumaeri dkk. (2009) adalah semakin besar konsentrasi proses zeolitisasi makin efektif.

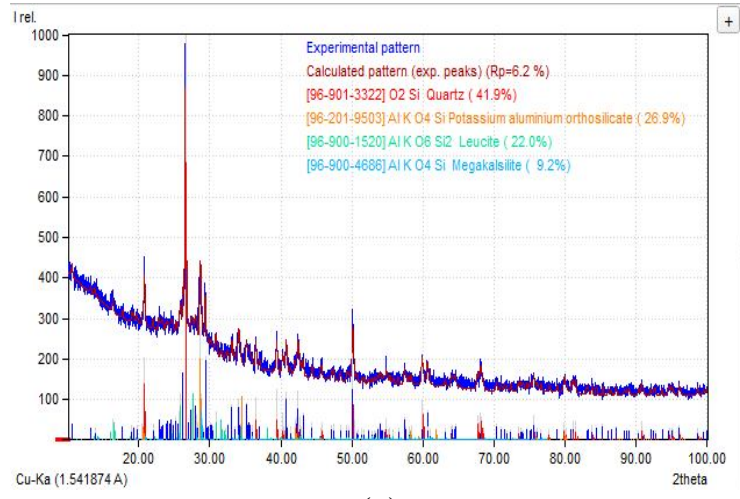

(a)

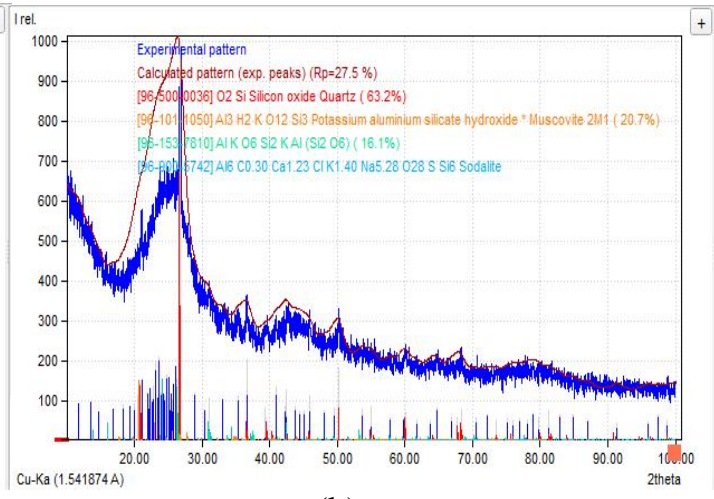

(b)

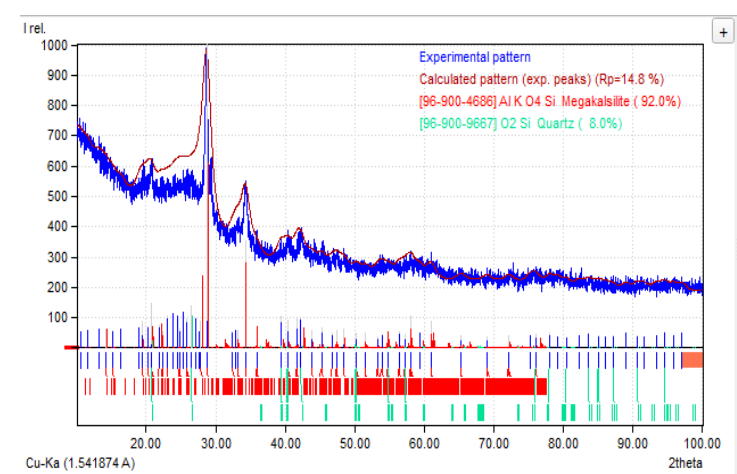

(c)

Gambar 1 Pola difraksi sinar-X dari zeolit sintetis $\mathrm{KOH}$ (a) $0,1 \mathrm{~mol}$ (b) 0,3 mol dan (c) 0,5 mol dengan media kristalisasi aquades

Sedangkan pada sampel yang menggunakan media kristalisasi air laut menghasilkan pola difraksi sinar-X seperti pada Gambar 2. Pada sampel ini terlihat bahwa semakin besar konsentrasi mengakibatkan menghilangnya puncak disejumlah sudut yang diindikasikan berdasarkan ICCD sebagai kuarsa $\left(\mathrm{SiO}_{2}\right)$ yang merupakan salah satu unsur penyusun utama dari abu dasar.

Puncak spekra tertinggi untuk media kristalisasi air laut adalah pada sudut $2 \theta=$ $26.5759(0,1 \mathrm{~mol}), 2 \theta=28.6691(0,3 \mathrm{~mol})$ dan $2 \theta=28.6637(0,5 \mathrm{~mol})$. Hasil pola untuk 0,3 mol dan 0,5 mol sesuai dengan puncak karakteristik dari standar ICDD yang merupakan pola dari kristal megakalsilit. Konsentrasi megakalsilit yang didapatkan menggunakan media kristalisasi air laut adalah 36,4\% (0,1 mol); 78,5\% (0,3 mol) dan 67,5\% (0,5 mol) (Tabel 3.1). Dari hasil persentase yang didapatkan tersebut dapat dilihat bahwa konsentrasi KOH 0,3 mol memiliki persentase paling besar dan menghasilkan megakalsilit lebih murni dari pada konsentrasi $\mathrm{KOH} 0,1 \mathrm{~mol}$ dan $0,5 \mathrm{~mol}$. Secara umum, megakalsilit memiliki nilai FD (Frame work) sebesar 20 atom T per 1000 A. Nilai FD menunjukkan kerapatan struktur, nilai FD yang lebih besar berarti struktur yang lebih rapat. Struktur yang lebih rapat akan berhubungan dengan pori yang lebih kecil. Zeolit dan produk lain yang didapat dari penelitian ini memiliki nilai FD yang relatif besar. 


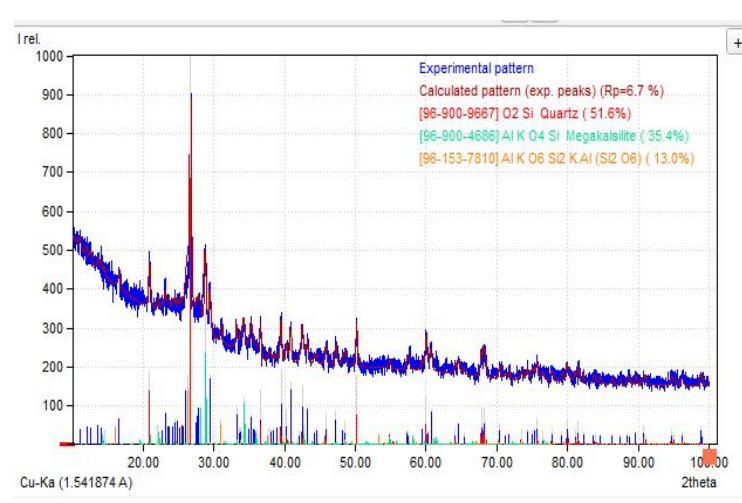

(a)

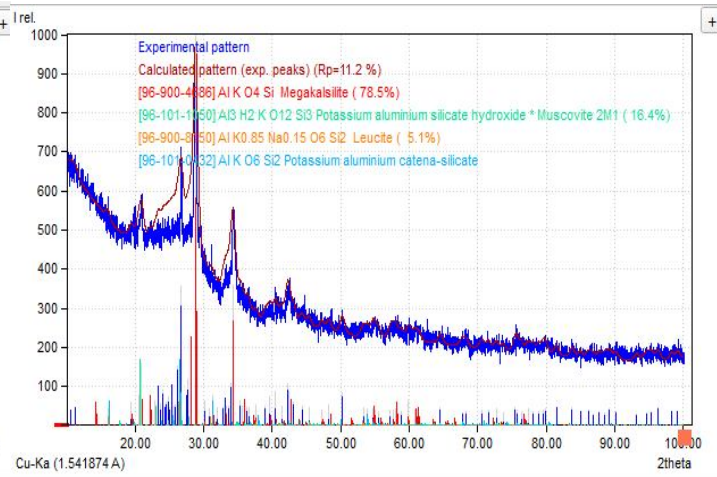

(b)

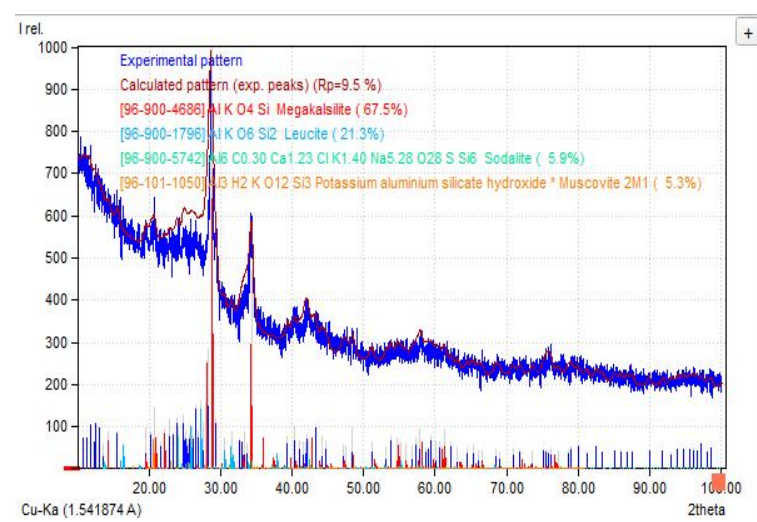

(c)

Gambar 2 Pola difraksi sinar-X dari zeolit sintetis $\mathrm{KOH}$ (a) 0,1 mol (b) 0,3 mol dan (c) 0,5 mol dengan media kristalinitasnya air laut.

Tabel 1 Daftar fase dan persentase hasil sintesis masing-masing sampel.

Produk yang dihasilkan

\begin{tabular}{lccccc}
\multicolumn{3}{c}{ Aquades } & \multicolumn{3}{c}{ Air laut } \\
\hline $\mathbf{0 , 1} \mathrm{mol}$ & $\mathbf{0 , 3} \mathrm{mol}$ & $\mathbf{0 , 5} \mathrm{mol}$ & $\mathbf{0 , 1} \mathrm{mol}$ & $\mathbf{0 , 3} \mathrm{mol}$ & $\mathbf{0 , 5} \mathrm{mol}$ \\
\hline
\end{tabular}

Kuarsa

$41,9 \%$

$63,2 \%$

$8 \%$

$51,6 \%$

$\mathrm{AlKO}_{4}$

Leucit

Megakalsilit

Muskovit

$\mathrm{AlKO}_{6} \mathrm{Si}_{2} \mathrm{Kal}$

$\left(\mathrm{Si}_{2} \mathrm{O}_{6}\right)$

Sodalit
$26,9 \%$

$22 \%$

$9,2 \%$

$-\quad 20,7 \%$

$92 \%$

$5,1 \%$

$21,3 \%$

$16,1 \%$

$13 \%$
$35,4 \%$

$13 \%$

$78,5 \%$

$67,5 \%$

$16,4 \%$

$5,3 \%$

Secara keseluruhan, penggunaan air laut berhasil meningkatkan kemurnian zeolit sintetis. Sampel dengan 0,3 mol KOH menggunakan media kristalisasi air laut mengalami peningkatan terhadap kemurnian zeolit dari pada semua sampel karena kandungan kuarsa pada sampel ini sudah berkurang. 


\section{KESIMPULAN}

Kosentrasi $\mathrm{KOH}$ mempengaruhi pembentukkan zeolit. Konsentrasi $\mathrm{KOH}$ dengan 0,1 mol dan 0,5 mol dengan media kristalisasi aquades menghasilkan zeolit megakalsilit dan kuarsa. Konsentrasi $\mathrm{KOH}$ dengan $0,3 \mathrm{~mol}$ dengan media kristalisasi air laut menghasilkan zeolit megakalsilit, leucit dan muskovit. Konsentrasi $\mathrm{KOH} 0,5$ mol menghasilkan zeolit dengan tingkat kemurnian yang lebih baik untuk media kristalisasi aquades dan $\mathrm{KOH} \mathrm{0,3} \mathrm{mol} \mathrm{untuk}$ media kristalisasi air laut.

\section{DAFTAR PUSTAKA}

Baerlocher, C., Mccusker, L. B., Olson, D. H., 2007, Atlas of Zeolite Framework Types, Published on Behalf of The Structure Commission of The International Zeolite Association,Elsevier, Amsterdam.

Fansuri, H., Prasetyoko, D. dan Muasyaroh, D., 2009, Effect of Initial Hydrothermal Temperatures to Zeolite Products in the Synthesis of Zeolites from Coal Fly Ash, CHEMECA, Perth.

Fatiha, W. Y., 2013, Sintesis Zeolit dari Fly Ash Batubara Ombilin pada Temperatur Rendah dengan Menggunakan Air Laut, Skripsi, FMIPA UNAND, Padang.

Grffiths, P. R., 1975, Chemical Infrared Fourier Transform, Toronto, John Willey \& SMS.

Jumaeri, Astuti, W. dan Lestari, W.T.P., 2007, Preparasi dan Karakterisasi Zeolit dari Abu Layang Batubara Secara Alkali Hidrotermal, Jurnal Reaktor, Vol. 11, No. 1, UNES, hal. 38-44.

Lestari, T. dan Muttaqin, A., 2015, Pengaruh Air Laut Terhadap Sifat Listrik Zeolit Sintetis Dari Bottom Ash Melalui Proses Alkali Hidrotermal, Jurnal Fisika Unand, Vol. 7, No. 1, Jur. Fisika Unand,,hal. 19-27.

Mumpton, F.A., 1985, Using Zeolites in Agriculture, Innovative Biological Technologies for Lesser Developed Countries, State University College, Washington DC.

Nikmah, R, A., 2008, Pengaruh Waktu dan Perbandingan Si/Al terhadap Pembentukan Zeolit A dari Abu Dasar Bebas Karbon dari PLTU PT. IPMOMI dengan Metode Hidrotermal, Jurnal Zeolit Indonesia, Vol. 7, No.1, Jur. Kimia, Institut Teknologi Sepuluh Nopember.

Oktaviani, Y. dan Muttaqin, A., 2015, Pengaruh Temperatur Hidrotermal terhadap Konduktivitas Listrik Zeolit Sintetis dari Abu Dasar Batubara dengan Metode Alkali Hidrotermal, Jurnal Fisika Unand, Vol. 4, No. 4, Jur. Fisika Unand, hal. 358-364.

Sari, N. K., 2016, Pengaruh Waktu Sonikasi terhadap Konduktivitas Listrik Zeolit Berbahan Abu Dasar Batubara Menggunakan Metode Peleburan Alkali Hidrotermal, Skripsi, FMIPA Unand, Padang.

Sriwahyuni, N., Muttaqin, A., dan Astuti, 2015, Pengaruh Temperatur Peleburan Alkali terhadap Konduktivitas Listrik Zeolit dari Bottom ash Batu Bara, Jurnal Fisika Unand, Vol 7, No 1, Jur. Fisika Unand, hal. 19-27.

Viklund, A., 2008, Teknik Pemeriksaan Material Menggunakan XRF, XRD dan SEM-EDS, Jurnal Sains, ITB, Bandung.

Waleza, R, J. dan Muttaqin, A., 2015, Pengaruh Waktu Refluks terhadap Konduktivitas Listrik Zeolit Sintetik dari Abu Dasar, Jurnal Fisika Unand, Vol. 4, No. 4, Jur. Fisika Unand, hal. 17-23.

Wustoni, S., Mukti, R. R., Wahyudi, A., Ismunandar, 2011, Sintesis Zeolit Mordenit dengan Bantuan Benih Mineral Alam Indonesia, Jurnal Matematika dan Sains, Vol. 16, No. 3, Fakultas Matematika dan Ilmu Pengetahuan Alam ITB.

Yusri, S., 2012, Sintesis dan Karakterisasi Zeolit ZSM-5 Mesopori dengan Secondary Template dan Studi Awal Katalisis Oksidasi Metana, Skripsi, UI, Depok. 